\title{
Maternal HIV infection is an important health determinant in non-HIV-infected infants
}

\author{
María Rupérez ${ }^{a, b, c}$, Raquel González ${ }^{a}$, Sonia Maculuve ${ }^{b}$, \\ Llorenç Quintó $^{\mathbf{a}}$, Elisa López-Varela ${ }^{\mathbf{a}, \mathbf{b}}$, Orvalho Augusto ${ }^{\mathbf{b}}$, Anifa Vala ${ }^{\mathrm{b}}$, \\ Arsénio Nhacolo ${ }^{b}$, Esperança Sevene ${ }^{b}$, Denise Naniche ${ }^{a}$ \\ and Clara Menéndez $z^{a, b, c}$
}

\begin{abstract}
Objective: To assess morbidity and mortality in HIV-exposed uninfected (HEU) children to help guiding appropriate clinical care and effective preventive interventions.

Design: This is a longitudinal study comparing two cohorts of children; one born to HIV-infected women and the other born to HIV-uninfected women.

Methods: We have analyzed prospectively obtained information on nutritional status, morbidity and mortality from $966 \mathrm{HEU}$ and 909 HIV-unexposed infants followed up until their first 18 months of life at a referral health facility in southern Mozambique. Determinants for adverse health outcomes in HEU children were also assessed using multivariate logistic regression.

Results: Increased incidence of hospital admissions $(P=0.0015)$, shorter survival in the first 18 months of life $(P=0.0510)$ and moderate and severe malnutrition $(P=0.0006$ and 0.0014 , respectively) were observed among HEU children compared with HIVunexposed children. Incidence of outpatient attendance in HEU children was associated with being men, older age and the mother being on antiretroviral treatment. Among HEU children, those who were never breastfed, or who were weaned or were partially breastfed, had an increased incidence of hospital admissions compared with children who were exclusively breastfed.

Conclusion: Maternal HIV infection has important health consequences in non-HIVinfected children. As the prevalence of HIV-infected pregnant women is maintained and the proportion of HIV-infected children declines because of the scale-up of antiretroviral treatment during pregnancy and breastfeeding, more focus should be given to the health needs of HEU children to ensure that the post-2015 sustainable development goals are met.

Copyright (c) 2017 Wolters Kluwer Health, Inc. All rights reserved.
\end{abstract}

AIDS 2017, 31:000-000

Keywords: Africa, HIV, HIV-exposed uninfected children, morbidity, mortality, pregnancy

\section{Introduction}

The scale-up of programs for the prevention of mother-tochild transmission of HIV (PMTCT) has increased remarkably in the last decade, which resulted in a $50 \%$ decline of new HIV infections among children since 2010 globally [1]. The currently recommended approach for PMTCT (the so-called Option B+), consisting in the

aISGlobal, Barcelona Ctr. Int. Health Res. (CRESIB), Hospital Clínic-Universitat de Barcelona, Barcelona, Spain, ${ }^{b}$ Manhiça Health Research Center (CISM), Manhiça, Mozambique, and ' ${ }^{C}$ Consorcio de Investigación Biomédica en Red de Epidemiología y Salud Pública (CIBERESP), Madrid, Spain.

Correspondence to María Rupérez, MD, PhD, ISGlobal, Barcelona Ctr. Int. Health Res. (CRESIB), Hospital Clínic-Universitat de Barcelona, Carrer Rosselló 132, 5ta segunda, Barcelona 08036, Spain.

E-mail: maria.ruperez@isglobal.org

Received: 7 December 2016; revised: 12 March 2017; accepted: 26 March 2017. 
initiation of lifelong antiretroviral therapy (ART) for all HIV-infected pregnant and breastfeeding women, is expected to further reduce the incidence of new HIV infections and potentially eliminate mother-to-child transmission (MTCT) of HIV [2]. Although current programatic efforts are focused in reducing new HIV pediatric infections, the number of children who are HIVexposed but uninfected is increasing proportionately. Every year, over 1 million infants are born to HIV-infected women worldwide, the majority of them in low-income countries, and most of them will not become infected [3]

HIV-exposed uninfected (HEU) children are increasingly recognized as a group with specific health needs. Direct or indirect HIV exposure in utero, intra partum or during breastfeeding may confer risks even in the absence of infection. Several studies have described increased mortality and enhanced risk of poor health and growth outcomes in HEU compared with HIV-unexposed children [4-11]. However, the nature of the vulnerability of the HEU children is not entirely clear. In addition to some immunological abnormalities that have been observed in HEU children, exposure to antiretroviral drugs both in utero and the neonatal period, feeding practices as well as a particular family environment, might all contribute to poor health outcomes [12].

Mozambique is one of the countries with the highest HIV prevalence and incidence in the world [13]. In some areas, up to $40 \%$ of pregnant women attending the antenatal care (ANC) clinics are HIV-infected [14,15]. After more than 10 years since the rollout of antiretrovirals in the country, a $57 \%$ reduction in new HIV infections among children has been reported between 2009 and 2013 [16]. However, there are very limited data on health outcomes and survival of HEU children. A better understanding of the impact of maternal HIV infection on the health outcomes of exposed children is needed in low-income settings, where malnutrition and comorbidities are frequent and health monitoring resources are limited. This study compares the survival and health outcomes between two cohorts of HIV-exposed and HIVunexposed children and identifies determinants for morbidity among the HEU children.

\section{Methods}

\section{Study design}

The current study compares prospectively obtained data on nutritional status, morbidity and mortality during the first 18 months of life, between two cohorts of children: one cohort born to HIV-infected women and the other born to HIV-uninfected women.

\section{Study area and population}

The study was conducted at the Manhiça District Hospital $(\mathrm{MDH})$, located in a semirural area of the
Maputo Province in southern Mozambique. Since 1996, the Centro de Investigação em Saúde de Manhiça has conducted continuous demographic surveillance covering a population of approximately 95000 inhabitants in an area of $500 \mathrm{~km}^{2}$ [17]. Passive morbidity surveillance was established in parallel at the MDH and peripheral health posts in the area, whereby all pediatric hospital admissions and outpatient attendances are registered onto standardized questionnaires following standard procedures.

The average HIV prevalence figure in 2015 in Mozambique was 11\% [18]. However, a communitybased survey undertaken in the Manhiça area among adults in 2012 reported nearly 40\% of HIV prevalence. The contemporaneous HIV seroprevalence among pregnant women attending the ANC clinics was 30\% [15]. A prevalence of $9 \%$ of MTCT at first month of age and of $25 \%$ at the end of the first year of life has also been reported in the area $[19,20]$. Before 2013, PMTCT relied on antiretroviral prophylaxis, which consisted in antepartum monotherapy with zidovudine (ZDV), a singledose nevirapine (NVP) at the onset of labor, and ZDV + lamivudine (3TC) at delivery and for 7 days post partum. Daily ZDV or NVP was recommended for infant prophylaxis during breastfeeding. National guidelines recommended ART to HIV-infected pregnant women for their own health if the $\mathrm{CD} 4^{+} \mathrm{T}$-cell count was less than 350 cells/ $\mu$ l and/or they were in 3-4 HIV/AIDS WHO clinical stage. The recommended first-line regimen consisted in the dual nucleoside analog reversetranscriptase Inhibitors backbone [3TC and either ZDV or stavudine (d4T)] and an nonnucleoside analog reversetranscriptase Inhibitors [either NVP or efavirenz (EFV)] [21]. In 2013, Mozambique adopted 'Option B+', consisting in the initiation of lifelong ART with tenofovir $(\mathrm{TDF})+3 \mathrm{TC}+\mathrm{EFV}$ in all HIV-positive pregnant and lactating women regardless of their immune status and clinical stage [22]. According to this recommendation, both breastfed and formula-fed infants should receive once-daily NVP from birth to 6 weeks of age. Cotrimoxazol prophylaxis (CTXp) is also recommended from 4 weeks until 2 months after weaning, whereas exclusively breastfeeding is recommended until 6 months of age.

\section{Study procedures}

HIV-unexposed children

A total of 909 children born between February 2010 and October 2012 to HIV-uninfected women participating in a trial comparing mefloquine with sulphadoxinepyrimethamine as intermittent preventive treatment of malaria in pregnancy were included in this study. Results from the trial showed no differences in mortality, morbidity and nutritional status between infants born to women allocated to either study group [23,24]. As part of clinical trial procedures, at delivery, newborns were given a study number to be uniquely identified. Mothers 
were asked to bring their child to study health facilities at 1 month of age, or coinciding with the first expanded program on immunization visit, and then at 9 and 12 months of age for study scheduled visits. Both at delivery and at study visits, weight and length were recorded onto standardized questionnaires.

\section{HIV-exposed uninfected children}

There were 966 children included in this study who were born to HIV-infected women, followed up at the HighRisk Pediatric Outpatient Clinic (HRPOC) of the MDH and born between January 2010 and December 2013. This study cohort included the children until they became HIV infected, died or ended the follow-up at 18 months of age.

As per national guidelines, children born to HIV-infected women were recommended to attend monthly visits at the HRPOC from the first month of life. In these visits, feeding habits and anthropometric and clinical characteristics were assessed. Informed consent was obtained, and data were collected prospectively onto standardized questionnaires in each of the subsequent visits to the HRPOC. Data from delivery, newborn baseline characteristics and uptake of PMTCT interventions during pregnancy were extracted retrospectively from the infant's Health Card. An HIV-DNA PCR test between 4 and 6 weeks of age was performed, with a confirmatory test on a new sample in those infants who test positive in the PCR. If the PCR test was negative, an HIV-antibody rapid test was performed at 9 months of age, and viral testing was carried out in those children with a positive serological test. The definitive diagnosis of HIV infection through HIV-antibody testing was determined at 18 months of age or when the risk of HIV exposure through breastfeeding ended. Infected infants were referred to the Pediatric HIV Outpatient Clinic for follow-up and ART initiation.

In both cohorts, information on hospital admissions and outpatient attendances during the first 18 months of life was obtained from the $\mathrm{MDH}$ passive morbidity surveillance system. Data on mortality were extracted from the demographic surveillance system in place.

\section{Laboratory methods}

HIV status was assessed from dried blood spot on filter paper using the Amplicor HIV-1 DNA-PCR kit (Roche Diagnostics, Branchburg, New Jersey, USA). Determine HIV-1/2 Rapid Test (Abbott Laboratories, Chicago, Illinois, USA) and Uni-Gold Rapid Test (Trinity Biotech, Dublin, County Wicklow, Ireland) were used for HIV serological testing on whole blood collected by finger prick. Hemoglobin was determined using mobile devices in capillary blood samples [HemoCue (www.eurotrol. com) and Hemocontrol (www.ekfdiagnostics.com)]. Thick and thin blood films were stained and read for
Plasmodium species detection according to standard, quality-controlled procedures [25].

\section{Data management, statistical methods and definitions}

Data were double-entered using the OpenClinica Enterprise software for clinical data management (www. openclinica.com).

Low birth weight (LBW) was defined as weight less than $2500 \mathrm{~g}$ at birth and preterm as a birth less than 37 weeks of gestation. Gestational age was assessed by the Ballard's score at delivery. Transformation of child anthropometric data to $z$-scores was performed using the least mean squares method and the reference data available from the 2000 Centers for Disease Control and Prevention growth reference in the United States [26,27]. Moderate malnutrition was defined as less than -2 SD for either weight-for-age, height-for-age or weight-for-height $z$-scores, and severe malnutrition as any of the previous $z$-scores under -3 SD [28]. Causes of hospital admission were classified according to the international classification of disease (ICD-10) coding system.

Minimum community-based incidence rates for the morbidity outcomes (outpatient attendances, hospital admissions and moderate/severe malnutrition) were calculated as the number of cases in children resident in the study area divided by the total children-years at risk (CYARs). CYARs were estimated from the demographic surveillance system databases. Children did not contribute to the numerator or denominator in the following situations: for a period of 15 days after each hospital admission, when they were outside the study area, after seroconversion (only in the HEU group) or after death. Cox proportional hazard models were used to assess the differences in mortality between the different age groups. Negative binomial regression models with random intercept were estimated to assess the association of HIV-exposure and other potential risk factors with the incidence of the studied outcomes. All the variables (sex, age, birth weight, type of delivery, location of delivery, gestational age, mother on CTXp, breastfeeding, maternal ART, child PMTCT and child CTXp) were included in the multivariate models to assess their adjusted associations with the incidence of outpatient attendances and hospital admissions among HEU children as they have all have been described in literature as potential confounders. Cox regression with left truncation (or delayed entry) was used for the evaluation of the associations with time to death.

The statistical software for analysis was STATA 14.1 (Stata Corp., College Station, Texas, USA).

\section{Ethics statement and participants' safety}

Protocols from both HEU and HIV-unexposed cohorts were reviewed and approved by the Ethics Committees 
AIDS 2017, Vol 00 No 00

Table 1. Baseline characteristics of HIV-exposed and HIV-unexposed newborns at birth.

\begin{tabular}{|c|c|c|c|c|c|}
\hline \multirow[b]{2}{*}{ Characteristics at birth } & \multicolumn{2}{|c|}{ HIV-exposed } & \multicolumn{2}{|c|}{ HIV-nonexposed } & \multirow[b]{2}{*}{$P$ value } \\
\hline & $N$ & $n(\%)$ & $N$ & $n(\%)$ & \\
\hline Sex (males) & 966 & $508(53)$ & 909 & $460(51)$ & $0.3905^{a}$ \\
\hline Birth weight (median, IQR ${ }^{b}$ ) & 509 & $3000(500)$ & 906 & $3100(500)$ & $0.2420^{\mathrm{C}}$ \\
\hline $\operatorname{LBW}^{\mathrm{d}}(<2500 \mathrm{~g})$ & 509 & $43(8)$ & 906 & $68(8)$ & $0.5269^{a}$ \\
\hline Gestational age (median, IQR ${ }^{\mathrm{b}}$ ) & 395 & $39(3)$ & 738 & $38(3)$ & $0.8713^{c}$ \\
\hline Preterm $(<37$ weeks $)$ & 395 & $74(19)$ & 738 & $103(14)$ & $0.0348^{\mathrm{a}}$ \\
\hline \multicolumn{6}{|l|}{ Delivery location } \\
\hline Maternity & 513 & $468(91)$ & 756 & $682(90)$ & $0.5420^{\mathrm{a}}$ \\
\hline Outside maternity & 513 & $45(9)$ & 756 & $74(10)$ & \\
\hline \multicolumn{6}{|l|}{ Type of delivery } \\
\hline Vaginal & 510 & $479(94)$ & 754 & 707 (94) & $0.9105^{\mathrm{a}}$ \\
\hline Cesarean section & 510 & $31(6)$ & 754 & $47(6)$ & \\
\hline
\end{tabular}

${ }^{\mathrm{a}}$ Chi-squared test.

${ }^{\mathrm{b}}$ Interquartile range.

'Wilcoxon rank-sum test.

dow birth weight.

from the Hospital Clinic of Barcelona (Spain) and local regulatory authorities and National Ethics Review Committee from Mozambique. The HIV-unexposed children trial was conducted under the provisions of the Declaration of Helsinki and in accordance with Good Clinical Practices guidelines set up by the WHO and by the International Conference on Harmonization.

\section{Results}

Baseline characteristics of study children at birth A total of 966 HEU and 909 HIV-unexposed children were followed up for their first 18 months of life. There were 53 (508/966) and 51\% (460/909) of men among HEU and HIV-unexposed children, respectively. There was no statistical significant difference in mean birth weight between HEU children [3000g (interquartile range (IQR): 500)] and HIV-unexposed children [3100 g (IQR: 500$) ; P=0.2420]$. The prevalence of LBW was $8 \%$ in both groups. The proportion of preterm newborns was significantly higher in HEU children $(19 \%, 74 / 395)$ compared with HIV-unexposed children (14\%, 103/738; $P=0.0348)$. The proportion of institutional deliveries was similar in both groups $(91 \%, 468 / 513$ in HEU children and 90\%,682/756 in HIV-unexposed children, respectively) with no difference either in the frequency of cesarean section by cohort, which was $6 \%$ in both groups (Table 1).

\section{Mortality, morbidity and malnutrition among study children}

A significantly lower incidence of outpatient attendances during the first 18 months of life was observed among HEU children compared with HIV-unexposed children [incidence rate ratio $($ IRR $)=0.77,95 \%$ confidence interval (CI): $(0.71,0.83) ; P<0.0001]$. In contrast, hospital admissions [IRR $=1.45,95 \% \mathrm{CI}$ : $(1.15,1.83)$; $P=0.0015]$ and episodes of moderate or severe malnutrition $\quad[\mathrm{IRR}=2.14, \quad 95 \%$ CI: $\quad(1.39, \quad 3.30)$; $P=0.0006$ and $\operatorname{IRR}=2.62,95 \% \mathrm{CI}:(1.45,4.75)$; $P=0.0014$, respectively] were more frequent among HEU children. A trend toward increased mortality was observed in the HEU cohort with 2.20 deaths per 100 children-year at risk compared with 1.16 deaths per 100 children-year at risk in the HIV-unexposed cohort [hazard ratio $=1.87,95 \% \mathrm{CI}:(1.00,3.52) ; P=0.0510]$ (Table 2). In both HEU and HIV-unexposed cohorts, mortality was higher in infants less than 6 months of age than in older children. Among HEU children, mortality rate was 2.67 per 100 CYARs [95\% CI: $(0.67,10.66)]$ in neonates and 4.94 [95\% CI: $(3.07,7.94)]$ in the 1-6-month age group, whereas among HIV-unexposed children, mortality rate in neonates was 5.28 [95\% CI: $(1.98,14.07)]$ and 1.67 [95\% CI: $(0.75,3.72)]$ in children between 1 and 6 months of age (Table 3 ).

Cause-specific hospital admissions are presented in Supplementary Table 1, http://links.lww.com/QAD/ B86. Higher incidences of diarrhea and moderate or severe malnutrition were observed among the HEU cohort compared with the HIV-unexposed one [IRR $=2.10$, 95\% CI: $(1.17,3.63) ; P=0.0128$; IRR $=2.14,95 \% \mathrm{CI}$ : $(1.39,3.30) ; P=0.0006$ and $\mathrm{IRR}=2.62,95 \% \mathrm{CI}:(1.45$, 4.75); $P=0.0014$, respectively].

\section{Risk factors for outpatient attendances and hospital admissions in HIV-exposed uninfected children}

Results from the univariate and multivariate analyses for outpatient attendances are presented in Table 4. In the multivariate analysis, female children had lower incidence of outpatient attendances [IRR $=0.82,95 \%$ CI: $(0.67$, 0.99); $P=0.0386]$ compared with men, whereas children whose mothers were on ART during pregnancy had higher incidence of this outcome [IRR $=1.33,95 \% \mathrm{CI}$ : $(1.01,1.75) ; P=0.0428]$ compared with children whose mothers were not on ART. Incidence of outpatient 
Table 2. Incidence of outpatient visits, hospital admissions, mortality and malnutrition in HIV-exposed uninfected and unexposed children in first 18 months of life.

\begin{tabular}{|c|c|c|c|c|c|c|c|c|c|c|c|}
\hline \multirow[b]{2}{*}{ Incidences } & \multicolumn{4}{|c|}{ HIV-exposed uninfected, $N=966$} & \multicolumn{4}{|c|}{ HIV-unexposed, $N=909$} & \multirow[b]{2}{*}{$\begin{array}{c}\text { Incidence rate } \\
\text { ratio }\end{array}$} & \multirow[b]{2}{*}{$95 \% \mathrm{Cl}$} & \multirow[b]{2}{*}{$P$ value } \\
\hline & Cases & CYAR $^{\mathrm{a}}$ & $\begin{array}{l}\text { Incidence } \\
\text { rate (per } \\
100 \mathrm{CYARs} \text { ) }\end{array}$ & $95 \% \mathrm{Cl}$ & Cases & PYAR & $\begin{array}{l}\text { Incidence } \\
\text { rate (per } \\
100 \text { CYARs) }\end{array}$ & $95 \% \mathrm{Cl}$ & & & \\
\hline $\begin{array}{l}\text { Outpatient } \\
\text { visits }\end{array}$ & 3063 & 1233.28 & 248.36 & $\begin{array}{l}(239.72 \\
257.32)\end{array}$ & 4157 & 1287.46 & 322.88 & $(313.22,332.85)$ & 0.77 & $(0.71,0.83)$ & $<0.0001$ \\
\hline $\begin{array}{l}\text { Hospital } \\
\text { admissions }\end{array}$ & 207 & 1233.68 & 16.78 & $(14.64,19.23)$ & 152 & 1292.70 & 11.76 & $(10.03,13.78)$ & 1.45 & $(1.15,1.83)$ & 0.0015 \\
\hline $\begin{array}{l}\text { Mortality } \\
\text { Malnutrition }\end{array}$ & 27 & 1226.11 & 2.20 & $(1.51,3.21)$ & 15 & 1288.41 & 1.16 & $(0.70,1.93)$ & $1.87^{\mathrm{b}}$ & $(1.00,3.52)$ & 0.0510 \\
\hline Moderate $^{\mathrm{c}}$ & 77 & 1238.88 & 6.22 & $(4.97,7.77)$ & 39 & 1297.26 & 3.01 & $(2.20,4.11)$ & 2.14 & $(1.39,3.30)$ & 0.0006 \\
\hline Severe $^{d}$ & 44 & 1240.04 & 3.55 & $(2.64,4.77)$ & 18 & 1298.12 & 1.39 & $(0.87,2.20)$ & 2.62 & $(1.45,4.75)$ & 0.0014 \\
\hline
\end{tabular}

95\% Cl, 95\% confidence interval.

${ }^{\mathrm{a}}$ Children-years at risk.

${ }^{\mathrm{b}}$ Hazard ratio.

'Weight-for-age (WAZ), length-for-age (LAZ) or weight-for-length $(\mathrm{WHZ}) \mathrm{z}$-scores under -2 SD.

dWAZ, LAZ or WHZ under -3 SD.

attendances increased with age from 6 to 18 months $(P=0.0001)$.

Results from the univariate and multivariate analyses for hospital admissions are shown in Table 5. In the multivariate analysis, the incidence of hospital admissions decreased in older age groups, with children in the 12 to less than 18-month age group having the lowest IRR compared with those in the 0 to less than 1-month age group [IRR $=0.13,95 \% \mathrm{CI}:(0.03,0.64) ; P=0.0517]$. Children who were not exclusively breastfed, those who had been weaned and children who were never breastfed showed an increased incidence of hospital admissions compared with children who were exclusively breastfed $[\mathrm{IRR}=2.21,95 \% \mathrm{CI}:(0.70,6.99) ; \mathrm{IRR}=6.74,95 \% \mathrm{CI}$ : (1.87, 24.31) and $\mathrm{IRR}=2.63,95 \% \mathrm{CI}:(0.92,7.52)$; $P=0.0177]$.

\section{Discussion}

There are very limited data on health outcomes and survival in HEU children in Mozambique, one of the countries with the highest HIV prevalence of the world.
A previously conducted study in the same area of smaller sample size also compared morbidity and mortality between HEU children and HIV-unexposed children. However, this study was performed only 4 years after intitiation of ART rollout in the country, and it did not evaluate health determinants among HEU children [19]. The findings of the current study show that HEU children are more likely to be undernourished, be admitted to hospital and die within the first 18 months of life compared with HIV-unexposed children. All of this shows that maternal HIV infection continues to have important adverse consequences on children's health even if the infection is prevented in the children.

In our study, mortality rate in HEU children almost doubled that of HIV-unexposed children. Cohort studies from other sub-Saharan countries have shown that, before the availability of ART, HEU children had a higher mortality risk than HIV-unexposed children [4,6,29]. However, reports on mortality in HEU and HIVunexposed children in the ART era are scarce, and results are heterogeneous [19,30-33]. Mortality rate in HEU children in this study (2.2 deaths per 100 live births per year at risk) was lower than that reported from other countries in sub-Saharan Africa in the ART era, though

Table 3. Incidence of mortality by age group in HIV-exposed uninfected and HIV-unexposed children in first 18 months of life.

\begin{tabular}{|c|c|c|c|c|c|c|}
\hline \multirow[b]{2}{*}{ Age } & \multicolumn{3}{|c|}{ HIV-exposed uninfected } & \multicolumn{3}{|c|}{ HIV-unexposed } \\
\hline & Mortality rate ${ }^{a}(95 \% \mathrm{Cl})$ & $\mathrm{HR}^{\mathrm{b}}(95 \% \mathrm{Cl})$ & $P$ value ${ }^{\mathrm{c}}$ & Mortality rate ${ }^{a}(95 \% \mathrm{Cl})$ & $\mathrm{HR}^{\mathrm{b}}(95 \% \mathrm{Cl})$ & $P$ value \\
\hline 0 to $<1$ month & $2.67(0.67,10.66)$ & 1 & 0.0155 & $5.28(1.98,14.07)$ & 1 & 0.0302 \\
\hline 1 to $<6$ months & $4.94(3.07,7.94)$ & $1.92(0.43,8.51)$ & & $1.67(0.75,3.72)$ & $0.25(0.07,0.94)$ & \\
\hline 6 to $<12$ months & $1.22(0.51,2.93)$ & $0.55(0.11,2.82)$ & & $0.92(0.35,2.46)$ & $0.12(0.03,0.57)$ & \\
\hline 12 to $<18$ months & $0.76(0.24,2.34)$ & $0.47(0.08,2.62)$ & & $0.24(0.03,1.69)$ & $0.04(0.00,0.51)$ & \\
\hline Total & $2.20(1.51,3.21)$ & - & - & $1.16(0.70,1.93)$ & - & - \\
\hline
\end{tabular}

95\% Cl, 95\% confidence interval.

${ }^{\text {a Per }} 100$ children-years at risk.

${ }^{\mathrm{b}}$ Hazard ratio.

${ }^{\mathrm{C} C o x}$ proportional hazard models. 
AIDS 2017, Vol 00 No 00

Table 4. Risk factors for outpatient visits in HIV-exposed uninfected children.

\begin{tabular}{|c|c|c|c|c|c|c|c|c|}
\hline \multirow[b]{2}{*}{ Variable } & \multirow[b]{2}{*}{$n$} & \multirow[b]{2}{*}{ Categories } & \multicolumn{3}{|c|}{ Univariate analysis } & \multicolumn{3}{|c|}{ Multivariate analysis $^{a}$} \\
\hline & & & $\begin{array}{l}\text { Incidence rate } \\
\text { ratio }\end{array}$ & $\begin{array}{c}\text { (95\% confidence } \\
\text { interval) }\end{array}$ & $P$ value & $\begin{array}{l}\text { Incidence } \\
\text { rate ratio }\end{array}$ & $\begin{array}{c}\text { (95\% confidence } \\
\text { interval) }\end{array}$ & $P$ value \\
\hline \multirow[t]{2}{*}{ Sex } & 684 & Male & 1 & & 0.0122 & 1 & & 0.0386 \\
\hline & & Female & 0.82 & $(0.71,0.96)$ & & 0.82 & $(0.67,0.99)$ & \\
\hline \multirow[t]{4}{*}{ Age } & 909 & 0 to $<1$ month & 1 & & $<0.0001$ & 1 & & 0.0001 \\
\hline & & 1 to $<6$ months & 1.07 & $(0.76,1.51)$ & & 0.96 & $(0.54,1.70)$ & \\
\hline & & 6 to $<12$ months & 1.61 & $(1.16,2.23)$ & & 1.60 & $(0.89,2.86)$ & \\
\hline & & 12 to $<18$ months & 1.54 & $(1.11,2.14)$ & & 1.40 & $(0.77,2.52)$ & \\
\hline \multirow{2}{*}{ Birth weight } & 494 & $\geq 2500 \mathrm{~g}$ & 1 & $(0.89,1.57)$ & 0.2404 & 1 & & 0.4885 \\
\hline & & $<2500 \mathrm{~g}$ & 1.18 & & & 1.13 & $(0.79,1.72)$ & \\
\hline \multirow[t]{2}{*}{ Type of delivery } & 495 & Vaginal & 1 & $(0.86,1.67)$ & 0.2861 & 1 & & 0.1263 \\
\hline & & Cesarean & 1.20 & & & 1.35 & $(0.92,1.98)$ & \\
\hline \multirow{3}{*}{ Location of delivery } & 497 & Maternity & 1 & & 0.0106 & 1 & & 0.6494 \\
\hline & & Home & 0.57 & $(0.39,0.82)$ & & 0.80 & $(0.50,1.28)$ & \\
\hline & & Other & 0.85 & $(0.37,1.92)$ & & 0.00 & - & \\
\hline \multirow{2}{*}{ Gestational age (weeks) } & 384 & $\geq 37$ weeks & 1 & & 0.7255 & 1 & & 0.5085 \\
\hline & & $<37$ weeks & 0.96 & $(0.76,1.21)$ & & 0.91 & $(0.70,1.19)$ & \\
\hline \multirow[t]{2}{*}{ Mother on CTXp ${ }^{b}$} & 474 & No & 1 & & 0.4436 & 1 & & 0.2340 \\
\hline & & Yes & 0.94 & $(0.79,1.11)$ & & 0.89 & $(0.73,1.08)$ & \\
\hline \multirow{4}{*}{ Breastfeeding } & 684 & Exclusive & 1 & & 0.0038 & 1 & & 0.2446 \\
\hline & & Partial & 1.17 & $(0.95,1.43)$ & & 0.82 & $(0.61,1.09)$ & \\
\hline & & Weaned & 1.38 & $(1.09,1.74)$ & & 0.88 & $(0.62,1.24)$ & \\
\hline & & Never did & 1.46 & $(1.15,1.84)$ & & 1.01 & $(0.74,1.38)$ & \\
\hline \multirow{2}{*}{ Maternal $\mathrm{ART}^{\mathrm{C}}$} & 684 & No & 1 & - & 0.0803 & 1 & & 0.0428 \\
\hline & & Yes & 1.23 & $(0.98,1.54)$ & & 1.33 & $(1.01,1.75)$ & \\
\hline \multirow[t]{2}{*}{ Child PMTCT ${ }^{d}$} & 684 & No & 1 & & 0.0081 & 1 & & 0.9348 \\
\hline & & Yes & 1.24 & $(1.06,1.44)$ & & 1.01 & $(0.74,1.38)$ & \\
\hline \multirow{2}{*}{ Child CTXp ${ }^{b}$} & 684 & No & 1 & & 0.0042 & 1 & & 0.1423 \\
\hline & & Yes & 1.39 & $(1.11,1.75)$ & & 1.35 & $(0.90,2.03)$ & \\
\hline
\end{tabular}

${ }^{\mathrm{a}} N=364$.

${ }^{\mathrm{b}}$ Cotrimoxazol prophylaxis.

${ }^{\mathrm{c}}$ Antiretroviral therapy.

${ }^{\mathrm{d}}$ Prevention of mother-to-child transmission of HIV.

comparable with the rate previously observed in this setting (2.5 deaths per 100 live births per year at risk) $[19,34]$. Importantly, the mortality rate observed in HEU children may be underestimated as only children who were passively followed up at the HRPOC were included in the analysis, and therefore those who may have died before follow-up intitiation or not engaged in healthcare were not part of it. This is supported by the the mortality rate distribution observed by age group, whereby in the first month of life, death rate in HIV-unexposed children was twice as high as that in HEU children, whereas this was the opposite in the other age group. This may be explained by neonatal deaths occurring before initiation of follow-up at the HRPOC among HEU children not being captured. Contrarily, estimates in HIV-unexposed children could be regarded as minimum estimates, as they refer to children who were enrolled in a clinical trial in which healthcare and follow-up might have been better than those in the general population.

The risk of all-cause hospital admissions in the first 18 months of life was significantly higher in HEU children compared with HIV-unexposed children, which is consistent with the findings of previous studies conducted in the context of available antiretrovirals for PMTCT [7,9,32]. Diarrhea (loose or watery stools more than three times in 1 day according to ICD-10 coding system) was more frequent among HEU compared with HIV-unexposed children. There is no conclusive evidence as to whether the risk of diarrhea is different in HEU compared with HIV-unexposed children in subSaharan Africa $[5,19,30,35,36]$. Increased risk of diarrhea-related morbidity in HEU might be a consequence of suboptimal breastfeeding rather than of HIV exposure itself. In contrast, as in the previous study performed in the same setting, the incidence of outpatient attendances was higher in HIV-unexposed children compared with HEU. This might be explained by the antibacterial effect of the routinely administered CTXp to HEU children from 6 weeks of age [19]. The special clinical follow-up of HEU children at the HRPOC might have also reduced outpatient healthcare utilization by HEU children.

HEU children were more likely to have higher incidence of both malnutrition-related hospital admissions and overall moderate and severe malnutrition during the first 18 months of life compared with HIV-unexposed children. HIV exposure during pregnancy has been associated with poor pregnancy outcomes such as preterm birth or LBW compared with nonexposed children [19,37-40]. In this study, prevalence of preterm birth was higher in HEU children compared with HIV-unexposed 
Table 5. Risk factors for hospital admissions in HIV-exposed uninfected infants.

\begin{tabular}{|c|c|c|c|c|c|c|c|c|}
\hline \multirow[b]{2}{*}{ Variable } & \multirow[b]{2}{*}{$n$} & \multirow[b]{2}{*}{ Categories } & \multicolumn{3}{|c|}{ Univariate analysis } & \multicolumn{3}{|c|}{ Multivariate analysis ${ }^{\mathrm{a}}$} \\
\hline & & & $\begin{array}{l}\text { Incidence } \\
\text { rate ratio }\end{array}$ & $\begin{array}{c}\text { (95\% confidence } \\
\text { interval) }\end{array}$ & $P$ value & $\begin{array}{l}\text { Incidence } \\
\text { rate ratio }\end{array}$ & $\begin{array}{l}\text { (95\% confidence } \\
\text { interval) }\end{array}$ & $P$ value \\
\hline Sex & 684 & Male & 1 & & 0.6541 & 1 & & 0.8055 \\
\hline \multirow[t]{3}{*}{ Age } & \multirow[t]{3}{*}{909} & 0 to $<1$ month & $\begin{array}{c}1 \\
1 \\
039\end{array}$ & (0 17 (7) & \multirow[t]{3}{*}{0.0254} & $\begin{array}{c}1 \\
1\end{array}$ & & \multirow[t]{3}{*}{0.0517} \\
\hline & & 6 to $<12$ months & $\begin{array}{l}0.39 \\
0.34\end{array}$ & $(0.16,0.72)$ & & $\begin{array}{l}0.3 / \\
0.24\end{array}$ & $\begin{array}{l}(0.09,1.52) \\
(0.01,1.05)\end{array}$ & \\
\hline & & 12 to $<18$ months & 0.33 & $(0.15,0.70)$ & & 0.13 & $(0.03,0.64)$ & \\
\hline \multirow{2}{*}{ Birth weight } & \multirow{2}{*}{494} & $\geq 2500$ & 1 & $(0.40,2.26)$ & \multirow{2}{*}{0.9033} & 1 & & \multirow{2}{*}{0.5567} \\
\hline & & $<2500$ & 0.95 & & & 0.68 & $(0.19,2.42)$ & \\
\hline \multirow{2}{*}{ Type of delivery } & \multirow{2}{*}{495} & Vaginal & 1 & & \multirow[t]{2}{*}{0.9695} & 1 & & \multirow{2}{*}{0.5521} \\
\hline & & Cesarean & 0.98 & $(0.35,2.77)$ & & 1.39 & $(0.47,4.16)$ & \\
\hline \multirow[t]{3}{*}{ Location of delivery } & \multirow[t]{3}{*}{497} & Maternity & 1 & & \multirow[t]{3}{*}{0.6799} & 1 & & \multirow[t]{3}{*}{0.8717} \\
\hline & & Home & 0.60 & $(0.18,1.95)$ & & 0.66 & $(0.14,3.11)$ & \\
\hline & & Other & 1.22 & $(0.15,9.54)$ & & 0.00 & - & \\
\hline \multirow[t]{2}{*}{ Gestational age (weeks) } & \multirow[t]{2}{*}{384} & $\geq 37$ weeks & 1 & & \multirow[t]{2}{*}{0.9279} & 1 & & \multirow[t]{2}{*}{0.5864} \\
\hline & & $<37$ weeks & 1.03 & $(0.53,2.01)$ & & 1.24 & $(0.57,2.69)$ & \\
\hline \multirow{2}{*}{ Mother on СТХр ${ }^{b}$} & \multirow[t]{2}{*}{474} & No & 1 & & 0.5228 & 1 & & 0.6979 \\
\hline & & Yes & 0.85 & $(0.52,1.40)$ & & 0.89 & $(0.48,1.64)$ & \\
\hline Breastfeeding & 684 & Exclusive & 1 & & 0.3682 & 1 & & 0.0177 \\
\hline & & Partial & 0.95 & $(0.45,2.04)$ & & 2.21 & $(0.70,6.99)$ & \\
\hline & & Weaned & 1.48 & $(0.63,3.46)$ & & 6.74 & $(1.87,24.31)$ & \\
\hline & & Never did & 1.48 & $(0.68,3.20)$ & & 2.63 & $(0.92,7.52)$ & \\
\hline Maternal $\mathrm{ART}^{\mathrm{C}}$ & 684 & No & 1 & & 0.6262 & 1 & & 0.5378 \\
\hline & & Yes & 0.81 & $(0.35,1.87)$ & & 1.37 & $(0.51,3.70)$ & \\
\hline Child PMTCT $^{d}$ & 684 & No & 1 & & 0.9461 & 1 & & 0.5552 \\
\hline & & Yes & 0.98 & $(0.62,1.57)$ & & 0.77 & $(0.31,1.86)$ & \\
\hline Child CTXp ${ }^{\mathrm{b}}$ & 684 & No & 1 & & 0.0242 & 1 & & 0.9356 \\
\hline & & Yes & 0.51 & $(0.29,0.92)$ & & 0.95 & $(0.28,3.22)$ & \\
\hline
\end{tabular}

${ }^{\mathrm{a}} N=364$.

${ }^{\mathrm{b}}$ Cotrimoxazol prophylaxis.

${ }^{\mathrm{c}}$ Antiretroviral therapy.

${ }^{\mathrm{d}}$ Prevention of mother-to-child transmission of HIV.

children, though data on gestational age at the time of delivery were only available in one-third of the HEU infants. However, the role of HIV exposure during pregnancy, delivery and breastfeeding on postnatal growth remains uncertain. Previous to availability of antiretroviral drugs, several studies showed poor growth outcomes in HEU children compared with HIVunexposed children $[41,42]$. However, reports in which antiretroviral drugs for PMTCT were used either found no differences in growth outcomes between HEU and HIV-unexposed children or if they existed were most likely due to different feeding practices rather than to HIV exposure [43,44].

The incidence of outpatient attendances in HEU children increased with age. Although exclusive breastfeeding is considered sufficient to provide adequate nutrition and immunological protection to infants during the first 6 months, the likely inadequacy, both in quantity and nutritional quality of weaning foods, together with exposure to infectious diseases may compromise the infant's health onward [45-48]. Another risk factor for outpatient attendance among HEU children was having a mother on ART during pregnancy. At the time of the study, women had to meet immunological and clinical criteria to start HIV treatment, being those more inmunosuppressed or with advanced clinical stage the ones who were eligible for ART. Offspring born to women with advanced HIV infection and eventually at higher risk of maternal mortality during childhood might be particularly vulnerable. In addition to an adverse social and economic background, compared with healthy mothers, those who are immunodeficient or clinically unwell might be less able to provide appropriate child care, adequate duration of breastfeeding or more likely to carry infectious pathogens harmful to their infants $[49,50]$.

The main limitation of this study is the difference in the follow-up between both cohorts. The HEU cohort was followed up by passive surveillance at the HRPOC, and the HIV-unexposed cohort included children participating in a clinical trial who were actively followed up from birth. Another limitation is that information on feeding practices was not available for HIV-unexposed children limiting the availability to infer their effect on the the differences between HEU and HIV-unexposed children. On the other hand, undetected HIV infections occurring in between the recommended HIV testings in HEU children might have influenced the results, as HIVinfected children tend to have worst health outcomes compared with HEU children [51]. Information on HEU 
children was obtained from passive surveillance at the HRPOC, and consequently there were missing data for some of the independent variables, which may limit the interpretation of the multivariate analysis.

In conclusion, increased morbidity and mortality was observed in HEU children compared with HIVunexposed children. New programs and interventions must take into consideration the long-term health needs of this growing population; they should also address transmission from mother to child, not only in terms of infant infections avoided, but also in terms of child survival. Due to the scale-up of option B+, MTCT of $\mathrm{HIV}$ is reducing and therefore the number of HIVinfected children. However, the prevalence of HIVinfected mothers is maintained, and thus the number of HEU children who have specific health needs that should be focused on to ensure that post-2015 sustainable development goals are achieved.

\section{Acknowledgements}

We are grateful to all the study participants and to all the staff from the Manhiça District Hospital and the Centro de Investigação em Saúde de Manhiça who contributed to the study.

M.R., R.G., E.S., D.N., E.M. and C.M. conceived and designed the study. M.R., R.G., S.M., A.N., A.V. and E.L. performed the study implementation and data collection. M.R., R.G., L.Q. and O.A. performed the data analysis. M.R. and C.M. drafted the article and M.R., R.G., S.M., L.Q., E.L., O.A., A.V., A.N., E.S., D.N., E.M. and C.M reviewed the article.

The work was supported by the European Developing Countries Clinical Trials Partnership (EDCTP; IP.2007.31080.002), the Malaria in Pregnancy Consortium and the following national agencies: Instituto de Salud Carlos III (PI08/0564), Spain. Raquel González and María Rupérez were partially supported by grants from the Spanish Ministry of Health (ref. CM07/0015 and CM11/00278, respectively). This work was also supported by the International Epidemiologic Databases to Evaluate AIDS (IeDEA), an international research consortium established and funded by the US National Institute of Allergy and Infectious Diseases (NIAID) (grant number: UO1AI069924, PIs: Mathias Egger and Mary-Anne Davies). The CISM receives core funding from the Spanish Agency for International Development Cooperation (AECID).

\section{Conflicts of interest}

There are no conflicts of interest.

\section{References}

1. Joint United Nations Programme on HIV/AIDS (UNAIDS). Fact sheet 2015. Global estimates. 2016. http://www.unaids.org/en/ resources/fact-sheet. [Accessed 5 April 2017].

2. WHO. Consolidated guidelines on the use of antiretroviral drugs for treating and preventing HIV infection 2016. Recommendations for a public health approach. 2nd ed. Geneva: World Health Organization; 2016.

3. Sugandhi N, Rodrigues J, Kim M, Ahmed S, Amzel A, Tolle M, et al. HIV-exposed infants: rethinking care for a lifelong condition. AIDS 2013; 27 (Suppl 2):S187-S195.

4. Marinda E, Humphrey JH, Iliff PJ, Mutasa K, Nathoo KJ, Piwoz EG, et al. Child mortality according to maternal and infant HIV status in Zimbabwe. Pediatr Infect Dis / 2007; 26:519-526.

5. Koyanagi A, Humphrey JH, Ntozini R, Nathoo K, Moulton LH, Iliff $\mathrm{P}$, et al. Morbidity among human immunodeficiency virusexposed but uninfected, human immunodeficiency virus-infected, and human immunodeficiency virus-unexposed infants in Zimbabwe before availability of highly active antiretroviral therapy. Pediatr Infect Dis / 2011; 30:45-51.

6. Brahmbhatt H, Kigozi G, Wabwire-Mangen F, Serwadda D, Lutalo T, Nalugoda F, et al. Mortality in HIV-infected and uninfected children of HIV-infected and uninfected mothers in rural Uganda. J Acquir Immune Defic Syndr 2006; 41:504-508.

7. Landes M, van Lettow M, Chan AK, Mayuni I, Schouten EJ, Bedell RA. Mortality and health outcomes of HIV-exposed and unexposed children in a PMTCT cohort in Malawi. PLOS One 2012; 7:e47337.

8. Fawzy A, Arpadi S, Kankasa C, Sinkala M, Mwiya M, Thea DM, et al. Early weaning increases diarrhea morbidity and mortality among uninfected children born to HIV-infected mothers in Zambia. I Infect Dis 2011; 203:1222-1230.

9. Slogrove A, Reikie B, Naidoo S, De Beer C, Ho K, Cotton M, et al. HIV-exposed uninfected infants are at increased risk for severe infections in the first year of life. / Trop Pediatr 2012; 58:505-508.

10. Filteau S, Baisley K, Chisenga M, Kasonka L, Gibson RS, CIGNIS Study Team. Provision of micronutrient-fortified food from 6 months of age does not permit HIV-exposed uninfected Zambian children to catch up in growth to HIV-unexposed children: a randomized controlled trial. I Acquir Immune Defic Syndr 2011; 56:166-175.

11. Liu L, Johnson HL, Cousens S, Perin J, Scott S, Lawn JE, et al. Global, regional, and national causes of child mortality: an updated systematic analysis for $\mathbf{2 0 1 0}$ with time trends since 2000. Lancet 2012; 379:2151-2161.

12. Evans C, Jones CE, Prendergast AJ. HIV-exposed, uninfected infants: new global challenges in the era of paediatric HIV elimination. Lancet Infect Dis 2016; 16:e92-e107.

13. UNAIDS. HIV epidemic profile. Mozambique: UNAIDS; 2014.

14. Gonzalez R, Munguambe K, Aponte J, Bavo C, Nhalungo D Macete $E$, et al. High HIV prevalence in a southern semi-rural area of Mozambique: a community-based survey. HIV Med 2012; 13:581-588.

15. Gonzalez R, Augusto OJ, Munguambe K, Pierrat C, Pedro EN, Sacoor C, et al. HIV incidence and spatial clustering in a rural area of southern Mozambique. PLoS One 2015; 10:e0132053.

16. UNAIDS, Mozambique. 2014 Progress Report on the Global Plan. Towards the elimination of new HIV infections among children by 2015 and keeping their mothers alive, J.U.N.P.o. HIV/AIDS, Editor. 2014

17. Sacoor C, Nhacolo A, Nhalungo D, Aponte Jl, Bassat Q, Augusto O et al. Profile: Manhica Health Research Centre (Manhica HDSS). Int J Epidemiol 2013; 42:1309-1318.

18. UNAIDS. Country Progress Report 2016. Relatório do Progresso da Resposta Global ao SIDA (Global AIDS Response Progress Report-GARPR). Conselho Nacional de Combate ao HIV e SIDA (CNCS) and the Joint United Nations Programme on HIV/AIDS (UNAIDS). Available: http://www.unaids.org/sites/default/files/ country/documents/MOZ narrative report 2016.pdf. [Accessed 5 April 2017].

19. Moraleda C, de Deus N, Serna-Bolea C, Renom M, Quintó L, Macete $\mathrm{E}$, et al. Impact of HIV exposure on health outcomes in HIV-negative infants born to HIV-positive mothers in SubSaharan Africa. J Acquir Immune Defic Syndr 2014; 65: 182-189. 
20. Gonzalez R, Desai M, Macete E, Ouma P, Kakolwa MA, Abdulla $\mathrm{S}$, et al. Intermittent preventive treatment of malaria in pregnancy with mefloquine in HIV-infected women receiving cotrimoxazole prophylaxis: a multicenter randomized placebo-controlled trial. PLOS Med 2014; 11:e1001735.

21. Moçambique, M.d.S.R.d., Guia de tratamento antiretroviral e infecções oportunistas no adulto, adolescente e gràvida 2009/ 2010. D.N.d.A. Médica, Editor. 2009: Moçambique.

22. Saúde, R.d.M.M.d., Guia de tratamento antiretroviral e infecções oportunistas no adulto, adolescente, gràvida e criança 2014 D.N.d.A. Médica, Editor. 2014: Moçambique.

23. Gonzalez R, Mombo-Ngoma G, Ouédraogo S, Kakolwa MA Abdulla $S$, Accrombessi $M$, et al. Intermittent preventive treatment of malaria in pregnancy with mefloquine in HIV-negative women: a multicentre randomized controlled trial. PLOS Med 2014; 11:e1001733.

24. Ruperez M, González R, Mombo-Ngoma G, Kabanywanyi AM Sevene E, Ouédraogo S, et al. Mortality, morbidity, and developmental outcomes in infants born to women who received either mefloquine or Sulfadoxine-Pyrimethamine as Intermittent Preventive Treatment of Malaria in Pregnancy: a cohort study. PLOS Med 2016; 13:e1001964.

25. Swysen C, Vekemans J, Bruls M, Oyakhirome S, Drakeley C, Kremsner $\mathrm{P}$, et al. Development of standardized laboratory methods and quality processes for a phase III study of the RTS, S/AS01 candidate malaria vaccine. Malar / 2011; 10:223.

26. Kuczmarski RJ, Ogden CL, Grummer-Strawn LM, Flegal KM, Guo SS, Wei R, et al. CDC growth charts: United States. Adv Data 2000; 314:1-27.

27. Cole TJ. The LMS method for constructing normalized growth standards. Eur J Clin Nutr 1990; 44:45-60.

28. Shann F. Nutritional indices: $\mathbf{Z}$, centile, or percentage? Lancet 1993; 341:526-527.

29. Sutcliffe CG, Scott S, Mugala N, Ndhlovu Z, Monze M, Quinn TC, et al. Survival from $\mathbf{9}$ months of age among HIV-infected and uninfected Zambian children prior to the availability of antiretroviral therapy. Clin Infect Dis 2008; 47:837-844.

30. Rollins NC, Ndirangu J, Bland RM, Coutsoudis A, Coovadia HM, Newell ML. Exclusive breastfeeding, diarrhoeal morbidity and all-cause mortality in infants of HIV-infected and HIV uninfected mothers: an intervention cohort study in KwaZulu Natal, South Africa. PLOS One 2013; 8:e81307.

31. Chopra M, Doherty T, Goga A, Jackson D, Persson LA. Survival of infants in the context of prevention of mother to child HIV transmission in South Africa. Acta Paediatr 2010; 99: 694-698.

32. Shapiro RL, Lockman S, Kim S, Smeaton L, Rahkola JT, Thior I, et al. Infant morbidity, mortality, and breast milk immunologic profiles among breast-feeding HIV-infected and HIV uninfected women in Botswana. J Infect Dis 2007; 196 $562-569$

33. Chilongozi D, Wang L, Brown L, Taha T, Valentine M, Emel L, et al. Morbidity and mortality among a cohort of human immunodeficiency virus type 1 -infected and uninfected pregnant women and their infants from Malawi, Zambia, and Tanzania. Pediatr Infect Dis J 2008; 27:808-814.

34. Thorne C, Idele P, Chamla D, Romano S, Luo C, Newell M-L. Morbidity and mortality in HIV-exposed uninfected children. Future Virol 2015; 10:1077-1100.
35. Marquez C, Okiring J, Chamie G, Ruel TD, Achan J, Kakuru A, et al. Increased morbidity in early childhood among HIVexposed uninfected children in Uganda is associated with breastfeeding duration. / Trop Pediatr 2014; 60:434-441.

36. van Eijk AM, Brooks JT, Adcock PM, Garrett V, Eberhard M, Rosen $\mathrm{DH}$, et al. Diarrhea in children less than two years of age with known HIV status in Kisumu, Kenya. Int / Infect Dis 2010; 14:e220-e225.

37. Naniche D, Bardají A, Lahuerta M, Berenguera A, Mandomando I, Sanz $\mathrm{S}$, et al. Impact of maternal human immunodeficiency virus infection on birth outcomes and infant survival in rural Mozambique. Am J Trop Med Hyg 2009; 80:870-876.

38. Braddick MR, Kreiss JK, Embree JB, Datta P, Ndinya-Achola JO, Pamba $\mathrm{H}$, et al. Impact of maternal HIV infection on obstetrical and early neonatal outcome. AIDS 1990; 4:1001-1005.

39. Temmerman M, Plummer FA, Mirza NB, Ndinya-Achola JO, Wamola IA, Nagelkerke $\mathrm{N}$, et al. Infection with HIV as a risk factor for adverse obstetrical outcome. AIDS 1990; 4:1087-1093.

40. Rollins NC, Coovadia HM, Bland RM, Coutsoudis A, Bennish ML, Patel D, Newell ML. Pregnancy outcomes in HIV-infected and uninfected women in rural and urban South Africa. I Acquir Immune Defic Syndr 2007; 44:321-328.

41. Henderson RA, Miotti PG, Saavedra JM, Dallabetta G, Chiphangwi I, Liomba $\mathrm{G}$, et al. Longitudinal growth during the first 2 years of life in children born to HIV-infected mothers in Malawi, Africa. Pediatr AIDS HIV Infect 1996; 7:91-97.

42. Bailey RC, Kamenga MC, Nsuami MJ, Nieburg P, St Louis ME. Growth of children according to maternal and child HIV, immunological and disease characteristics: a prospective cohort study in Kinshasa, Democratic Republic of Congo. Int Epidemiol 1999; 28:532-540.

43. Patel D, Bland R, Coovadia H, Rollins N, Coutsoudis A, Newell ML. Breastfeeding, HIV status and weights in South African children: a comparison of HIV-exposed and unexposed children. AIDS 2010; 24:437-445.

44. Arpadi S, Fawzy A, Aldrovandi GM, Kankasa C, Sinkala M, Mwiya M. Growth faltering due to breastfeeding cessation in uninfected children born to HIV-infected mothers in Zambia. Am I Clin Nutr 2009; 90:344-353.

45. Kramer MS, Kakuma R. Optimal duration of exclusive breastfeeding. Cochrane Database Syst Rev 2012; 8:CD003517.

46. Robinson S, Fall C. Infant nutrition and later health: a review of current evidence. Nutrients 2012; 4:859-874.

47. Przyrembel $\mathrm{H}$. Timing of introduction of complementary food: short- and long-term health consequences. Ann Nutr Metab 2012; 60 (Suppl 2):8-20.

48. Wright CM, Parkinson KN, Drewett RF. Why are babies weaned early? Data from a prospective population based cohort study. Arch Dis Child 2004; 89:813-816.

49. Evans C, Jones CE, Prendergast AJ. HIV-exposed, uninfected infants: new global challenges in the era of paediatric HIV elimination. Lancet Infect Dis 2016; 16:e92-e107.

50. Kakkar F, Lamarre V, Ducruet T, Boucher M, Valois S, Soudeyns $\mathrm{H}$, Lapointe N. Impact of maternal HIV-1 viremia on lymphocyte subsets among HIV-exposed uninfected infants: protective mechanism or immunodeficiency. BMC Infect Dis 2014; 14:236.

51. Newell ML, Brahmbhatt H, Ghys PD. Child mortality and HIV infection in Africa: a review. Aids 2004; 18 (Suppl 2):S27-S34. 